ternity ceremonial before the birth of his son. The head of the daughter of this once birthmarked man was a bit flattened on one side. It was flattened, believed her grandfather, because her father would go prairie-dog hunting before her birth and he always shot his prairie-dogs in the head.

Now the cures for birthmarks or malformations are, the cause being a ceremonial, to put on the ceremonial mask in question and dance hard in the presence of the child, subsequently rubbing the sweat of one's body on to the child; and, the cause being a hunted animal, to hunt the same animal and rub its blood on the child. Similarly, to cure an infant of crying incessantly-it cries because its back pains and its back pains because before its birth its father has overdriven his horses, belaying them presumably on the back-to cure it one must drive a team hard and rub on to the child's back the sweat from under their collar or some piece of their harness.

If a child becomes deaf-cases of deafness at birth are unknown-it is because during her pregnancy its mother stole. To cure the child she must steal again and burning the object stolen puts its ashes into the ears of the child: If the cord of a new-born infant " runs," it is because one who has been bitten by a snake has been present in the room. That person should be found and then four times he should wave some ashes around the heads of mother and child. Otherwise the child will die.

The deer-hunter who sees a buck and doe together and the buck mount the doe, knows that by this token the deer are "telling" him of what is happening at home. His faithless wife is far from "staying still" in the house she should leave but once, at noon time, for water, while her husband is off hunting. It becomes his business, therefore, to shoot the deer and take out their hearts. On his return home he will find his wife and her lover sick. To cure them, if he pity them, he will have to rub them with deer heart made up into a ball with meal, rubbing the woman with the heart of the doe, the man with the heart of the buck.

Should a person be struck or shocked by lightning, he or she must be given some rain water of that same storm to drink, rain water plus black beetle and suet. Otherwise the person will "dry up" and die. ${ }^{1}$ About three years ago a certain house on the south side of the river was struck. The three women in it neglected to take the prescribed drink. To-day the three are dead, two dying a year or two ago, the third this summer.

Should a person in dying "frighten" any one, from the head of his corpse a lock of hair is cut. The hair is burned and the smoke of it is inhaled by the person who has been upset. This practise, however, is uncommon. ${ }^{2}$

Elsie Clews Parsons

\section{SPECIAL ARTICLES \\ THE IMPORTANCE OF LATERAL VISION IN ITS RELATION TO ORIENTATION}

IT is a well-established principle that binocular vision gives to human beings a means of determining the relative distances between near-by objects, as well as the distances of these objects from the observer. The basis of this power lies in seeing the objects from two points of view, giving a stereoscopic effect, which, however, is decreasingly effective as the objects are removed from the eyes. It is apparently partly the decreasing stereoscopic effect with increasing distance which forms the basis of measurement; and partly a judgment of distance in some way through the muscular movements of the eyes, and those governing the accommodation of the lenses. The power of measuring distance by. binocular vision is, however, scarcely effective at distances greater than four or five hundred feet. It is entirely

1 The experience qualifies a survivor for becoming a doctor. One of the present tenientes or members of the governor's staff or council is a lightning-struck doctor.

2 Mrs. Stevenson's description of this practise is somewhat different, remaining, however, one may infer, an illustrative of inoculation magic. "If a person takes a bit of hair of a deceased friend, burns it, and inhales the smoke he will have good health and not die, but go to sleep and thus pass on to Ko'thluwa'la", ("The Zuñi Indians," p. 309, XXIII. (1901-02), Am. Rep. Bur. Amer. Ethnol.). 
lacking beyond fourteen hundred feet, according to Gleichen. ${ }^{1}$

In the case of a man moving through a forest or any maze-like region, owing to the frontal position of his eyes, the axis of his vision is parallel to his motion; hence the apparent displacement of the trees of the forest as seen by him, due to his forward motion, is a minimum. The effect is similar to that when a person is riding on a railway and looking out from a front window of a car straight at the track and its immediate surroundings. It is obvious that relative displacement of objects near the track in the retinal picture due to motion of the observer is very slight. In frontal vision, as in man, a displacement of the head sidewise affords a powerful means of measurement of distance, as has been pointed out, probably first by Helmholtz.

The eyes of most birds, fish and reptiles are so situated in the skull that only lateral vision is possible. A number of species of birds, however, have the ability to turn the eyes so as to give binocular vision at will, and some species have two distinct vision foveæ, "yellow spots," in each eye, for distinct sight for the two types of vision. Other species have two of the round and one streak-like foveæ; particularly certain ground-feeding birds of the snipe family; etc. ${ }^{2}$ Some of the mammalia have lateral vision, some have their eyes so placed that the retinal pictures partially overlap and binocular vision is possible; others have frontal vision as in man. It is interesting to consider in what manner the lateral position of the organs of vision enters into the determination, for example, by a bird, of the distances of surrounding objects. It is an important question, owing to the intimate connection of such determinations with the "sense of direction" problem.

There seems to be good evidence that those living creatures having side vision have a decided advantage over man in their ability to gauge or measure the relative distances of

1 A. Gleichen, "Die Theorie der Modernen Optischen Instrumente," p. 184.

2 "Lehrbuch der Vergleichenden mikroskopischen Anatomie,"' Part 7, pp. 82-84. their surroundings, owing to the lateral position of the eyes. When a bird or a mammal, etc., with its eyes so placed, moves forward, the principal visual axis is perpendicular to its motion. This gives the maximum apparent displacement of objects with every forward motion of the creature.

This displacement of surrounding objects gives to the animal having lateral vision a means of a continual register of the relative distances apart of surrounding objects. To use the analogy of a person riding on a railway, it is as if one was looking out of a side window of a car. There is the additional advantage for the animal, since it may be said to be looking out of two side windows, one on each side. There is, moreover, the possibility, in the case of creatures having lateral vision, of a differential effect, since a change in the direction of the head while in the forward motion would be registered on the retina of each eye. The advantages of lateral vision for measuring the relative distance of surrounding objects is illustrated as follows:

The arrows in Figs. 1 and 2 are meant to represent a man moving forward along a straight path 15 feet, and a bird also moving forward 15 feet respectively. Both observe trees (the crosses) at 100 feet distance from $A$, the starting-point.

The trees are in front, nearly, of the man in the one case, and at the side of the bird in the other. The angles $a$ and $b$ are the angular measures of apparent displacements in the two cases, due to the forward movements. With the distances given in Figs. 1 and 2, these angular measurements are as 5 is to 1 in favor of the bird, but this is assuming that the man has only one eye. For distances within a few hundred feet of the man, as in Figs. 1 and 2, binocular vision is a means of measurement of distances, and hence the bird's advantage is less than the ratio given. It is, in fact, hardly possible to state a true measure of the advantage.

In Fig. 1 it is necessary to place the trees considerably to one side of the man's path; otherwise there would be no angular displacement of the trees for the man whatever. 


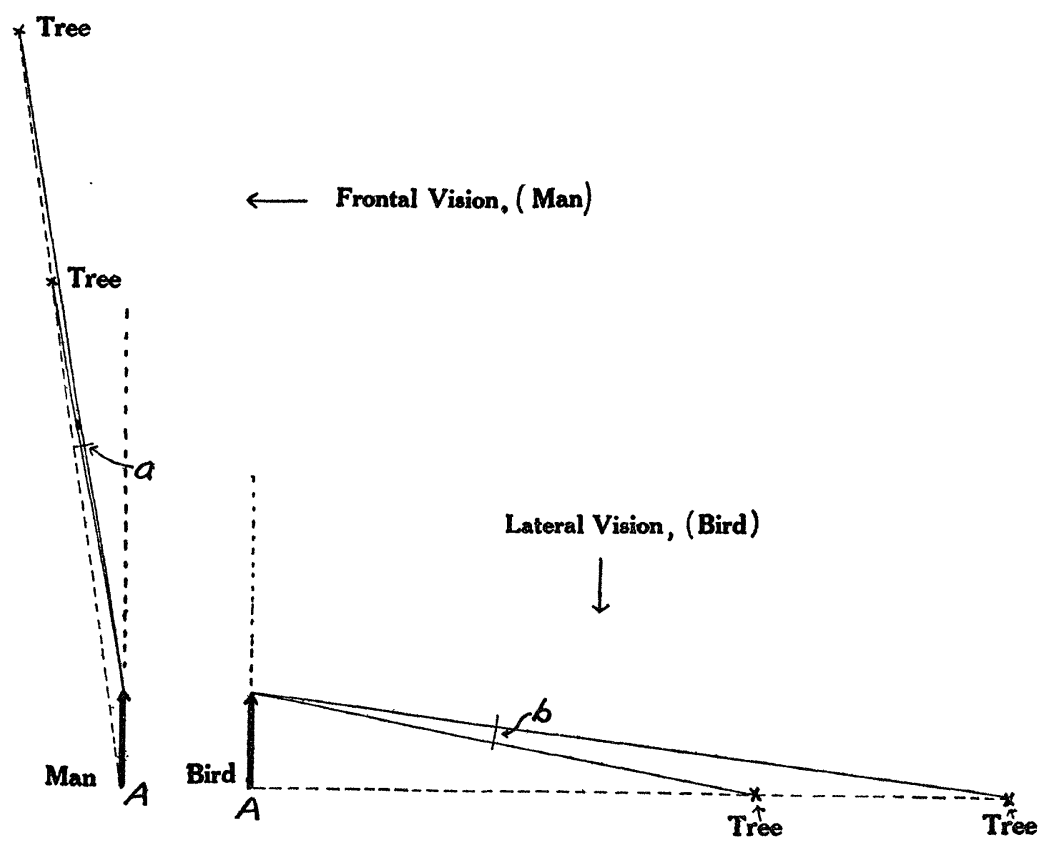

FIgs. 1 and 2. These diagrams show the parallax (displacement) of objects as viewed in frontal vision and in lateral vision. The ratio of $b$ to $a$, with distances given in the text, is 5 to 1 .

In order to give figures showing the advantage of lateral vision over frontal vision at greater distances due to motions forward, two cases were selected where the objects are two trees, one at 1,000 feet and the other 2,000 feet distant, respectively, from the observer (man and bird), the trees being approximately in the axis of vision in each case. To obtain any values it is necessary (as in Fig. 1) to place the two objects observed (trees) out of line of the direction of the man's motion; that is, to one side of his path. . The results in Fig. 3 and Fig. 4 were obtained from a graphical construction which is omitted.

Fig. 3 is an equal parallax curve and it shows the distance that a man and bird must each move forward to give the same apparent displacement of trees against the horizon. In the figure the points are plotted as they were found from the graphical construction, and show a slight irregularity.

Fig. 4 is a curve constructed from Fig. 3, and it illustrates the decided advantage of the bird over the man.
The bird's advantage is obtained by dividing the distance that the man must move forward by the distance that the bird moves forward to obtain equal displacement of the objects viewed. For example, at the point $M$, the man has moved forward 20 feet and the bird's advantage is 12 to 1 . At point $N$ the man has moved forty feet, and the bird's advantage is 10 to 1 , etc.

The distances of one thousand and two thousand feet were taken as a basis for the curves in Figs. 3 and 4 because binocular vision is not a means of measurement at these distances, and hence the advantages for the bird are as they have been given in the figures.

This method of demonstrating the advantage of lateral vision serves chiefly to give some numerical expression of the value of that type of vision for the measurement of the distances apart of objects in the field of view.

In conclusion it may be stated then that an animal having only lateral vision, if at rest, has no means of measuring the relative distance of surrounding objects, except by comparison of the various size of objects, and 


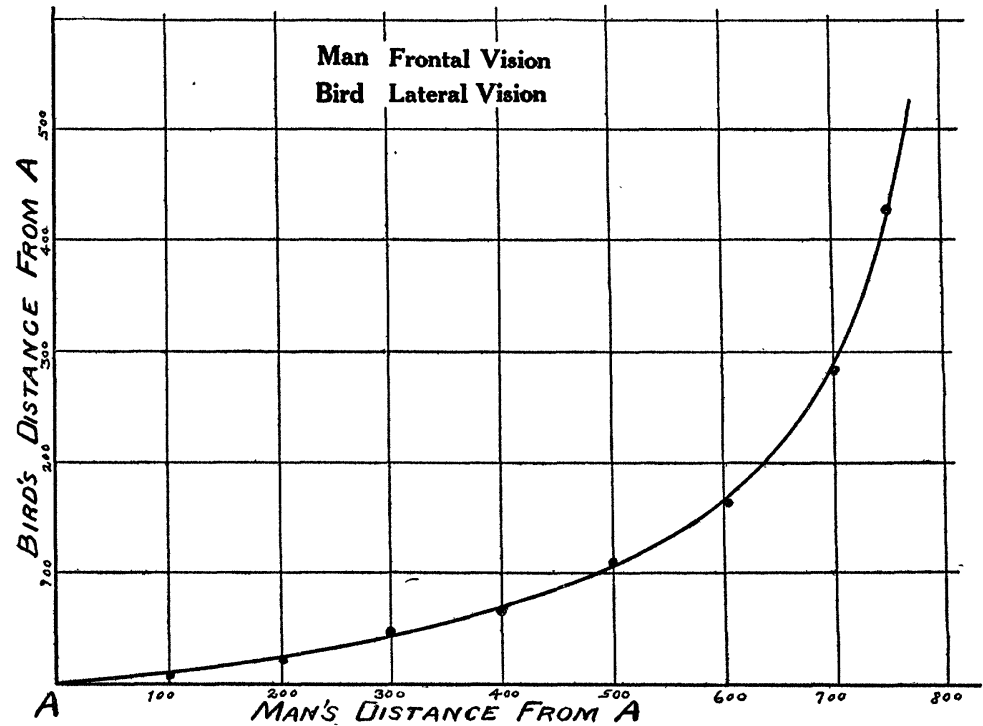

FIG. 3. Equal parallax curve, showing the distances a man and a bird must move forward to give the same apparent displacement of objects against the horizon.

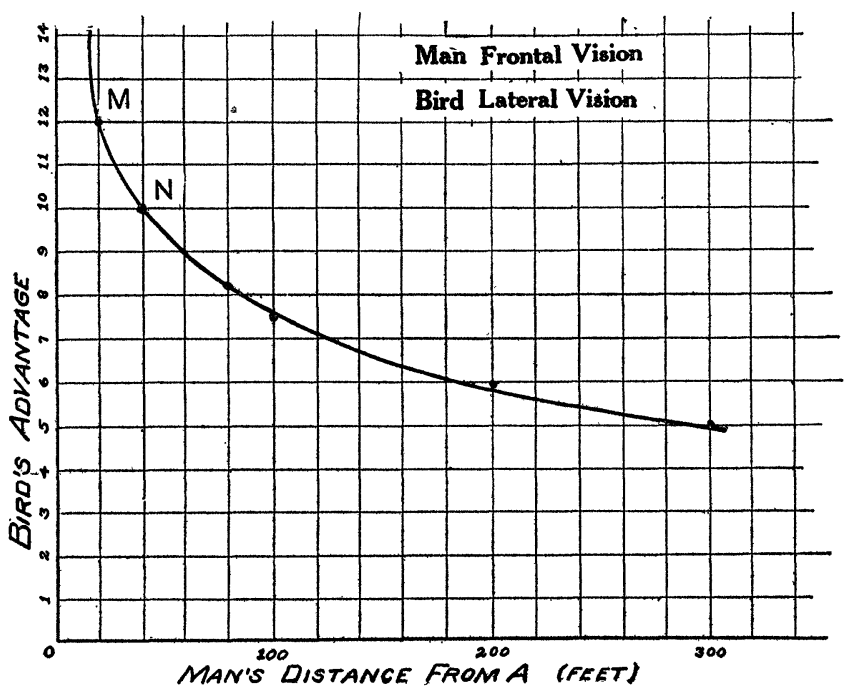

FIG. 4. Advantage curve. The bird's advantage is obtained by dividing the distance that the man must move forward by the distance that the bird moves forward to obtain the same displacement of objects viewed. At $M$, the advantage is 12 to 1 ; at $N, 10$ to 1 , etc.

through accommodation, etc. An animal having binocular vision (man, ape, cat, etc.), if at rest, has such a means for the measurement of objects that are not more than a few hundred feet distant.

If creatures having each type of vision are moving forward, then there is a distinct advantage in favor of the one having lateral vision. This is especially the case if the objects viewed are in the middle ground (500 to 1,500 feet away), or at greater distances, since binocular vision furnishes little, if any, means 
for measuring the relative position of objects at these distances. Thus an animal with lateral vision, when moving forward, has a stereoscopic view of the landscape, owing to the excessive relative displacement of objects. A person looking out of a side window of a moving railway car sees the landscape in the same way.

This power of measuring surrounding distances due to lateral vision is important in its bearing on the "sense of direction" problem because the orientation of a bird with respect to points of reference about it depends on the subconscious summing up of the space relations immediately about the bird as it moves here and there through the woods or through any familiar or unfamiliar region. This subconscious summation on the part of the bird is greatly aided by any means which measures the relative distances of minor reference points in its immediate vicinity as it passes on its way.

The writer is not aware that the power that animals having lateral vision seem to possess of measuring the distances in their surroundings has been pointed out hitherto. That there is such advantage over frontal vision, as in man, appears to be evident. In any case, the relation of lateral vision to near-by orientation has not been properly emphasized. This short paper is a part of an investigation on "sense of direction" in animals, which has been aided by the Herman Fund of the New York Academy of Sciences. C. C. Trowbridge

Phennix Physical Laboratory, Columbia UNIVERSITY

\section{THE AMERICAN ASSOCIATION FOR THE ADVANCEMENT OF SCIENCE- SECTION B, PHYSICS}

THE biggest and the best of the several meetings the American Physical Society holds every year is always that one held jointly with Section $\mathrm{B}$ of the American Association for the Advancement of Science. There are of course very few active members of this section who are not also active members of the Physical Society and therefore it might seem that there could be no advantage in holding joint meetings. Indeed it might even be argued that the Physical Society had better meet at some other place where there were none but physicists-no distracting reminders of other sciences and other interests.

But, as just stated, the uniform experience is strongly in favor of the joint meetings. And one thing that makes the annual meeting so delightful and so profitable is the frequent, even if more or less casual, conversations with scientists whose chief interests are in other subjects-delightful because of the charming acquaintances formed and profitable because of the new interrelations one is quite certain to see between his own and other sciences.

The recent meeting at Columbus, Ohio, at which President R. A. Millikan, of the Physical Society and Vice-president E. P. Lewis, of the American Association for the Advancement of Science, alternately presided, was one of these pleasant and profitable occasions.

The address of the retiring vice-president of the association and chairman of Section B, Dr. Anthony Zeleny, was a well-deserved tribute to the designer and the maker of instruments of precision upon whom advancement in science so greatly depends. It appeared in full in ScIENCE for February 11.

The symposium-always a delightful feature of these joint meetings-was on the behavior of substances at very high pressures. Dr. P. W. Bridgman gave a most interesting summary of the numerous discoveries he has made of the properties of substances at enormously heavy pressuresproperties stranger than fiction and of great importance.

At present the officers of Section B are as follows:

Vice-president and Chairman of the Section: $\mathrm{H}$. A. Bumstead, Yale University.

Secretary: W. J. Humphreys, Washington, D. C. Member of Council: A. L. Foley, University of Indiana.

Sectional Committee: Vice-president, San Franciseo and Columbus, E. P. Lewis; Vice-president, New York, H. A. Bumstead; Secretary, W. J. Humphreys; Preceding Secretary, Alfred D. Cole; T. C. Mendenhall, one year; Dayton C. Miller, two years; George W. Stewart, three years; Robert R. Tatnall, four years; W. S. Franklin, five years. Ex-officio: R. A. Millikan, President, American Physical Society; Alfred D. Cole, Secretary, American Physical Society.

Member of General Committee: G. B. Pegram, Columbia University.

$$
\text { W. J. HUMPHREYs, }
$$
Secretary 